\title{
Temporal evolution of GP zones in an Al-Ag alloy
}

\author{
E.A. Marquis*, N.B. Bartelt* and F. Leonard* \\ * Sandia National Laboratory, PO Box 969, Livermore, CA 94550
}

In the phase-separating Al-Ag system, intermediate metastable precipitates (Guinier Preston zones) are formed. The metastable miscibility gap is characterized by a large asymmetry with a gap extending to $\sim 55$ at. $\% \mathrm{Ag}$ below $175^{\circ} \mathrm{C}$ and to $\sim 30$ at. $\% \mathrm{Ag}$ above $220^{\circ} \mathrm{C}$ [1]. The exact structure of the GP zones (ordering, Ag concentration) and the existence of temperature-dependent phases (ordered at low $\mathrm{T}$ and disordered at high $\mathrm{T}$ ) is still matter of debate and the experimental studies published on this system have yet to concur. Previous atom probe studies have confirmed the variations of GP zone concentration with temperature [2] and a more recent work by Al-Kassab et al. showed the coexistence of two types of precipitates [3]. Recent TEM observations have also indicated that in the initial stages of decomposition, GP zones form with a surprising morphology consisting of a Ag-rich shell surrounding an Al-rich inner core [4].

This paper discusses our recent transmission electron microscopy and atom probe tomography measurements of the three-dimensional Ag concentration in precipitates, including the temporal evolution.

An Al-2.7 at.\% Ag alloy (prepared by arc melting of $99.999 \%$ purity $\mathrm{Al}$ and $\mathrm{Ag}$ ) was homogenized at $580^{\circ} \mathrm{C}$ for 48 hours in Ar atmosphere. After iced water quenching, the alloy was aged in an oil bath at $130^{\circ} \mathrm{C}$ and $220^{\circ} \mathrm{C}$ for times varying from 30 minutes to 1000 hours. TEM and atom probe tips were prepared by electropolishing using a solution of 1:3 nitric acid in methanol. Field evaporation was performed on a LEAP microscope at 20K, with a pulse fraction between 15 and $20 \%$ and a repetition rate of $200 \mathrm{kHz}$.

Quenching the alloy lead to phase separation with the appearance of Ag-rich domains. The domains do not have a precise shape at early times but evolve to spherical precipitates with faceting at long aging times. During aging at $130^{\circ} \mathrm{C}$, the domain size coarsening kinetics follow a power law with an exponent close to $1 / 3$. Surprisingly, the concentration of the precipitates is size dependent: the Ag concentration decreases with decreasing size, suggesting a strong role of the interfacial energy. T late times, the Ag concentrations in the GP zones follows that predicted by the metastable phase diagram: $38 \pm 4$ at. $\% \mathrm{Ag}$ at $220^{\circ} \mathrm{C}$ and $63 \pm 3$ at. $\% \mathrm{Ag}$ at $130^{\circ} \mathrm{C}$.

\section{References}

[1] K.B. Alexander, F.K. Legoues, H.I. Aaronson, D.E. Laughlin, D. E. Acta Metallurgica 32 (1984) 2241-2249.

[2] K. Osamura, T. Nakamura, A.Kobayashi, T. Hashizume, T. Sakurai, Scripta Metallurgica 21

(1987) 255-258.

[3] T. Al-Kassab, P. Haasen, P. Zeitschrift fur Metallkunde 84 (1993) 248-250.

[4] R. Erni, H. Heinrich, G. Kostorz, Philosophical Magazine Letters 83 (2003) 599-609.

[5] Sandia is a multiprogram laboratory operated by Sandia Corporation, a Lockheed-Martin Company, for the United States Department of Energy National Nuclear Security Administration under contract DE-AC04-94AL85000. Special thanks to Mark Homer for his invaluable contribution to specimen preparation. 
(a)

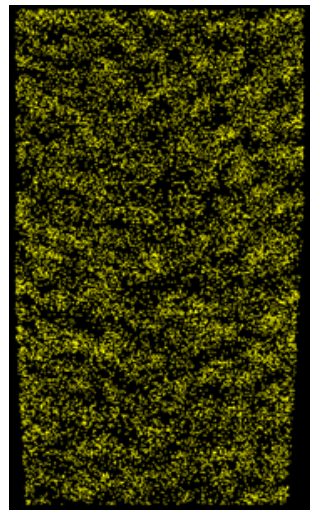

(b)

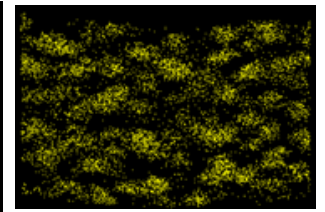

$40 \mathrm{~nm}$ (c)

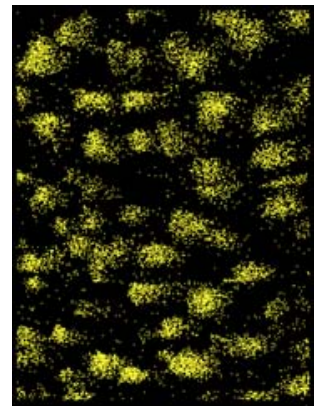

(d)

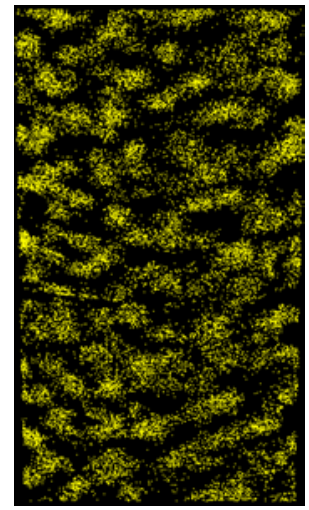

(e)

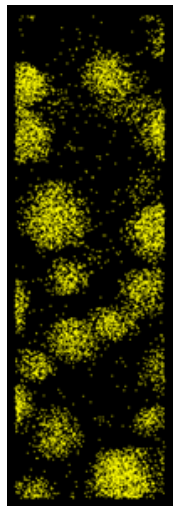

(f)

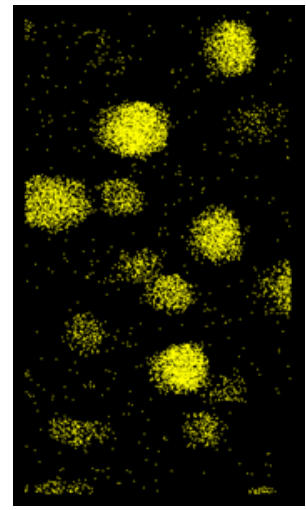

FIG. 1. 3D reconstructions from tips (a) in the as quenched condition and (b-f) after aging at $130^{\circ} \mathrm{C}$ for 30 minutes, 2, 8, 44 and 116 hours. Ag atoms are represented by yellow dots while the $\mathrm{Al}$ atoms are omitted for clarity of the image.

(a)

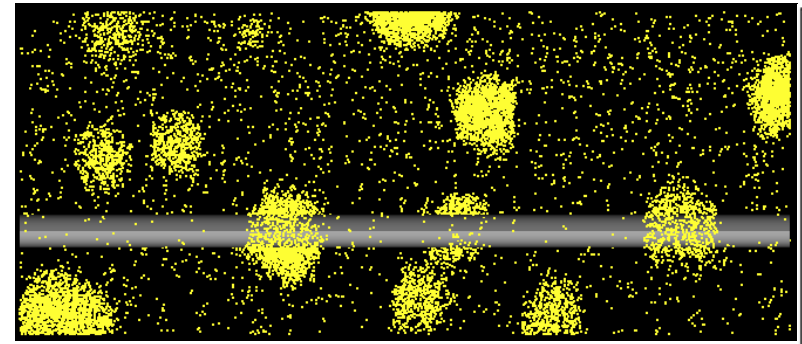

(b)

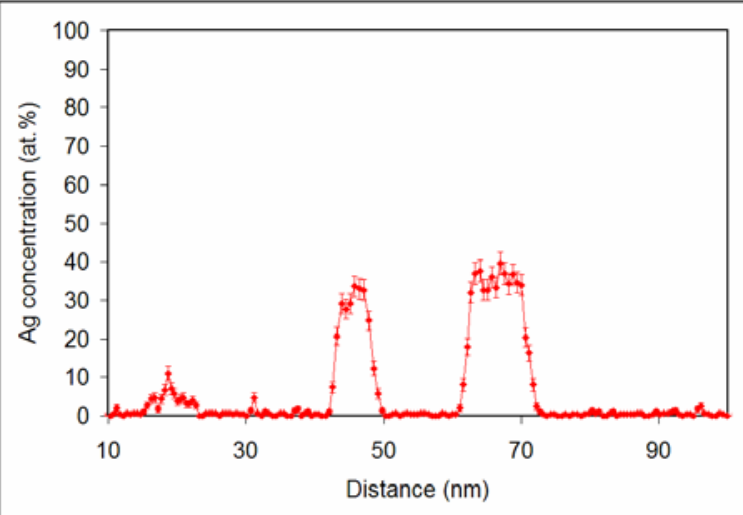

FIG. 2. (a) Slide from a 3D reconstruction obtained from a tip aged at $220^{\circ} \mathrm{C}$ for 1 hour. $\mathrm{Ag}$ atoms are represented by yellow dots while the $\mathrm{Al}$ atoms are omitted for clarity of the image. The GP zones are well defined and a concentration profile taken along the cylinder intercepting GP zones in shown in (b). The average concentration in the precipitates is $63 \pm 3$ at.\% $\mathrm{Ag}$. 